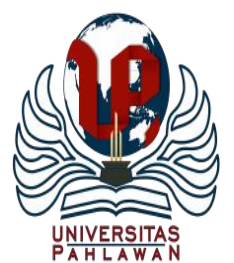

Edukatif : Jurnal Ilmu Pendidikan Volume 3 Nomor 4 Tahun 2021 Halm 2313 - 2320 EDUKATIF: JURNAL ILMU PENDIDIKAN

Research \& Learning in Education

https://edukatif.org/index.php/edukatif/index

\title{
Strategi Guru Pendidikan Agama Islam (PAI) dalam Internalisasi Nilai-Nilai Moral di Sekolah Dasar
}

Sobri

Universitas Terbuka, Indonesia

E-mail : ahmadshobri7981@gmail.com

\begin{abstract}
Abstrak
Penelitian ini bertujuan unuk menginternalisasi nilai-nilai moral keagamaan dalam proses pembelajaran PAI agar ilmu yang diperoleh siswa lebih bermakna di SDN Pegadungan 07 Pagi. Sehubungan dengan hal di atas, Strategi pembelajaran PAI dalam internalisasi nilai-nilai moral keagamaan dikembangkan dalam pembelajaran PAI yang dituangkan melalui berbagai aktifitas di lembaga pendidikan dalam kesehariannya, baik dalam kegiatan yang bersifat kurikuler maupun ekstra kurikuler. Jenis penelitian ini adalah penelitian kualitatif, berdasarkan pembahasannya termasuk penelitian deskriptif dengan menggunakan rancangan studi multi situs. Teknik pengumpulan data menggunakan observasi, wawancara, dan dokumentasi. Analisa data dilakukan mulai dari reduksi data, penyajian data, dan menarik kesimpulan. Untuk menguji keabsahan data dilakukan perpanjangan kehadiran, triangulasi, pembahasan teman sejawat dan klarifikasi dengan informan. Hasil penelitiannya adalah 1) Strategi keteladanan (modeling) dalam internalisasi nilai-nilai moral di SDN Pegadungan 07 Pagi dengan jalan: a) keteladanan internal (internal modelling). b) keteladanan eksternal (external modelling), 2) Strategi penanaman Nilai Edukatif yang kontekstual dalam internalisasi nilai-nilai moral 3) Strategi penguatan nilai-nilai yang ada dalam internalisasi nilai-nilai moral dilakukan dengan menganjurkan untuk internalisasi nilai-nilai moral keagamaan dengan melalui kemampuan dan pengalaman guru dalam memberikan nasihat dan mendorong siswa untuk senantiasa bertanggung jawab.
\end{abstract}

Kata Kunci: Strategi, Nilai Moral Keagamaan, PAI

\section{Abstract}

The research aims to internalize of religious moral values in the learning process PAI so that the knowledge gained by students is more meaningful. In connection with the above, it is necessary to have a strategy to achieve the goals of Islamic religious education. The PAI learning strategy in internalizing religious moral values is developed in Islamic Islamic education learning which is poured out through various activities in educational institutions in their daily lives, both in activities that are curricular and extra-curricular. This type of research is qualitative research, based on its discussion including descriptive research using a multi-site study design. Data collection techniques using observation, interviews, and documentation. Data analysis was carried out starting from data reduction, data presentation, and drawing conclusions. To test the validity of the data, attendance extension, triangulation, peer discussion and clarification with informants were carried out. The results of the research were 1) modeling strategies in internalizing moral values at SDN Pegadungan 07 Pagi by: a) internal modeling. b) external modeling, 2) The strategy of instilling contextual educational values in the internalization of moral values at SDN Pegadungan 07 Pagi 3) The strategy of strengthening the values that exist in internalizing moral values is carried out by advocates for internalizing religious moral values through the ability and experience of teachers in providing advice and encouraging students to always be responsible.

Keywords: Strategy, Religious Moral Value, PAI.

Copyright (c) 2021 Sobri

$\triangle$ Corresponding author

Email : ahmadshobri7981@gmail.com

DOI : https://doi.org/10.31004/edukatif.v3i4.900 


\section{Strategi Guru Pendidikan Agama Islam (PAI) dalam Internalisasi Nilai-Nilai Moral di Sekolah Dasar- Sobri}

DOI: https://doi.org/10.31004/edukatif.v3i4.900

\section{PENDAHULUAN}

Pendidikan adalah suatu pondasi dalam hidup yang harus dibangun dengan sebaik mungkin. Pendidikan merupakan suatu wadah dalam membentuk peradaban yang humani seseorang sebagai bekal dalam menjadi kehidupan (Tambak, 2016). Persoalan pendidikan terutama dalam karakter dan moral bagi peserta didik menjadi bahan pemikiran sekaligus keprihatinan bersama karena masyarakat Indonesia saat ini sedang mengalami krisis karakter. Krisis ini ditandai dengan maraknya tindakan kriminalitas, seperti tawuran antara pelajar, meningkatnya pergaulan bebas, maraknya angka kekerasan anak-anak dan remaja, serta pelecehan seksual. Hal ini dapat dilihat dari hasil laporan yang masuk ke sistem infomasi online milik Kementerian PPPA (Simponi) data sebelum pandemi 1 Januari-28 Februari 2020 diperoleh 1.913 kasus kekerasan terhadap perempuan, kemudian setelah pandemi terjadi peningkatan lima kali lipat menjadi 5.500 kasus. Begitupun kekerasan pada anak sebelum masa pandemi ada 2.851 kasus dan meningkat menjadi 7.190 kasus di masa pandemi ini. Penyebab kekerasaan baik pada perempuan maupun pada anak sangat beragam, salah satu penyebab terjadinya kekerasaan pada anak yaitu anak sulit mencari tempat yang aman seperti sekolah ketika mendapatkan kekerasan di rumah. Dampak dari kekerasan pada anak akan menimbulkan trauma dan menyisakan abnormalitas tumbuh kembang yang akan mempengaruhi dewasanya kelak (Andini, 2019). Fenomena tersebut jelas telah mencoreng citra pelajar dan lembaga pendidikan, karena banyak orang yang berpandangan atau mempunyai prespektif bahwa kondisi demikian berawal pada apa yang kemudian dihasilkan oleh lembaga pendidikan. Karena pendidikan yang sesungguhnya mempunyai misi yang mendasar yaitu membentuk manusia yang seutuhnya dengan akhlak mulia sebagai indikator utama. Pendidikan merupakan suatu hal yang tidak dapat dipisahkan dari kehidupan berbangsa dan bernegara (Akerlof, 2012).

Pendidikan merupakan jalur vital dan startegis dalam mempersiapkan sumber daya manusia (Saleh, 2016). Oleh karena itu, penyelenggaraan pendidikan agama yang dimanifestasikan dengan pengembangan nilai-nilai agama di berbagai jenjang pendidikan patut untuk dilaksanakan. Nilai dari keimanan seseorang dapat dinyatakan dengan sikap yang secara lahiriah dan rohaniah sebagai tenaga pendorong atau penegak yang fundamental bagi tingkah laku seseorang (Tambak, 2016). Karena dengan tertanamnya nilai-nilai agama pada diri siswa maka akan memperkokoh imannya, dan aktualisasi nilai-nilai keagamaan tersebut dapat tercipta dari lingkungan di sekolahnya. Sekolah merupakan bagian pokok dalam mengembangkan karakter, sikap, kemampuan serta keterampilan seseorang (Wahyudi \& Alafiah, 2016). Untuk itu, pengembangan nilai-nilai agama sangat penting dan akan mempengaruhi sikap, sifat dan tindakan siswa secara tidak langsung. Pendidikan agama Islam mempunyai peranan startegis dalam membangun kualitas sumber daya manusia Indoensia dalam penguasaan IPTEK maupun karakter, sikap dan penghayatan serta pengamalan ajaran agama (Kholidah, n.d, 2015). Selain itu nilai-nilai PAI merupakan sesuatu untuk memasukkan nilai secara penuh ke dalam hati peserta didik, sehingga mereka dapat bersikap dan berprilaku berdasarkan ajaran agama islam, dan selanjutnya dapat diinternalisasikan dalam kehidupan sehari-hari.

Internalisasi adalah suatu proses pembinaan penanaman pola pikir, sikap dan prilaku ke dalam diri pribadi seseorang melalui pembinaan, bimbingan dan sebagainya agar menguasai secara mendalam suatu nilai agama dengan standar yang diinginkan. Dalam menginternalisasikan nilai-nilai moral) terdapat 4 (empat) pendekatan yang dapat digunakan, yaitu pendekatan penanaman moral, pendekatan transmisi nilai bebas, pendekatan teladan, dan pendekatan klarifikasi nilai (Murdiono, 2010). Pendidikan nilai perlu dilakukan dengan menggunakan pendekatan secara komprehensif. Pendekatan ini bisa terlaksana apabila ada kerjasama baik dari pihak sekolah, guru, dan orang tua menerupakan serta memberikan contoh perilaku yang baik dalam keseharaian baik disekolah atau dirumah, tidak hanya itu pengawasan juga menjadi titik utama untuk membentuk moral bagi peserta didik pada lingkungannya. Nilai-nilai yang terkandung dalam pelajaran PAI dapat diamalkan dalam kehidupan sehari-hari oleh siswa, baik di kelas maupun di luar kelas, sehingga menjadi karakter yang melekat pada diri siswa (Munif, 2017). 


\section{Strategi Guru Pendidikan Agama Islam (PAI) dalam Internalisasi Nilai-Nilai Moral di Sekolah Dasar- Sobri}

DOI: https://doi.org/10.31004/edukatif.v3i4.900

Sehubungan dengan hal di atas, maka perlu adanya strategi untuk mencapai tujuan pendidikan agama Islam yaitu dengan cara mengubah paradigma dan cara pandang kita terhadap pembelajaran PAI itu sendiri (Tang, 2018). Strategi pembelajaran PAI dalam internalisasi nilai-nilai moral keagamaan dikembangkan dalam pembelajaran PAI yang dituangkan melalui berbagai aktifitas di lembaga pendidikan dalam kesehariannya, baik dalam kegiatan yang bersifat kurikuler maupun ekstra kurikuler pada sekolah SDN Pegadungan 07 Pagi.

\section{METODE PENELITIAN}

Jenis penelitian ini adalah penelitian lapangan (field research) yaitu penelitian yang objeknya mengenai gejala-gejala atau peristiwa-peristiwa yang terjadi pada kelompok masyarakat. Field research adalah suatu penelitian yang bertujuan untuk menjelaskan makna yang diberikan oleh anggota masyarakat pada perilakuknya dan kenyataan sekitar (Salmon Priaji Martana, 2006). Sehingga penelitian ini juga bisa disebut penelitian kasus atau study kasus (case study) dengan pendekatan deskriptif kualitatif. Penelitian kulaitatif merupakan penelitian yang berfokus pada permasalahan kehidupan sosial yang didasarkan pada kondisi realitas atau natural setting yang holistik, kompleks, dan rinci (Luthfiyah, 2015).

Informan penelitian dalam penelitian ini adalah kepala sekolah, guru PAI, serta guru kelas dan siswa kelas 4, 5, 6 sebagai informan pendukung, pemilihan informan tersebut dilakukan secara acak saat peneliti mengumpulkan data.

Instrumen dalam penelitian ini adalah peneliti sendiri. Peneliti sebagai instrumen dapat berhubungan langsung dengan responden dan mampu memahami serta menilai berbagai bentuk dari interaksi di lapangan. Instrumen dalam penelitian ini adalah dengan metode wawancara. Wawancara yaitu percakapan dengan tujuan tertentu (Shidiq \& Choiri, 2019).

Dalam penelitian kualitatif, pengumpulan data dilakukan dengan cara observasi dan wawancara. Teknik ini merupakan ciri utama dari penelitian kualitatif (Basrowi \& Suwandi, 2014). Pengumpulan data pada penelitian ini dengan cara observasi dan wawancara.

Analisis data merupakan tahap yang paling penting dalam penelitian (Yusuf Sukman, 2017). Analisis data dalam penelitian kualitatif merupakan proses pelacakan dan pengaturan secara ssitematis catatan lapangan yang telah diperoleh dari waawancara, observasi dan bahan lain supaya peneliti dapat melaporkan hasil penlelitian (Firman, 2015). Analisis data dalam penelitian ini menggunakan teknik analisis data yang dibuat dalam matriks. Matriks akan disajikan berisi penggalan-penggalan data deskriptif sekitar peristiwa atau pengalaman tertentu yang menyekat data sebelum dan sesudahnya.

Uji kredibilitas data atau kepercayaan data penelitian kualitatif terdiri atas perpanjangan pengamatan, meningkatkan ketekunan, triangulasi, analisis kasus negatif, menggunakan bahan referensi dan member check (Mekarisce, 2020). Pengujian terhadap kredibilitas data dalam penelitian ini dilakukan dengan triangulasi sumber data dan pemanfaatan metode, serta member check. Dengan demikian dalam pengecekan keabsahan data mutlak diperlukan dalam penelitian kualitatif agar supaya data yang diperoleh dapat dipertanggung jawabkan kebenarannya dengan melakukan verifikasi terhadap data. Verifikasi terhadap data tentang strategi pembelajaran PAI dalam internalisasi nilai-nilai moral keagamaan dilakukan dengan langkah-langkah sebagai berikut: 1) Mengoreksi metode yang digunakan untuk memperoleh data. 2) Mengecek kembali hasil laporan penelitian yang berupa uraian data dan hasil interpretasi peneliti. 3) Triangulasi untuk menjamin obyektifitas dalam memahami dan menerima informasi. 


\section{HASIL DAN PEMBAHASAN PENELITIAN}

\section{Kondisi SDN Pegadungan 07 Pagi di Masa Lalu}

Sebelum menjelaskan hasil penelitian penulis menjelaskan kronologis kondisi dimasa lalu. Berdasarkan observasi awal yang dilakukan, bahwa peneliti memilih SDN Pegadungan 07 Pagi Kalideres Jakarta Barat sebagai tempat penelitian karena di lembaga pendidikan tersebut merupakan lembaga yang mempunyai system pendidikan yang maju, kegiatan Estrakurikuler di SDN Pegadungan 07 Pagi Kalideres Jakarta Barat mempunyai system yang dapat membentuk prestasi akademik antara lain lomba pidato juara kedua tingkat kecamatan, juara kedua lomba Tahfiz dan juara kedua lomba Qira'at tingkat kelurahan. Sistem pendidikan di SDN Pegadungan 07 Pagi Kalideres Jakarta Barat mempunyai program shalat dhuhur berjamaah, shalat dhuha, pembacaan Asmaul Husna bersama, berdo'a sebelum dan sesudah belajar dan peserta didik wajib berperilaku Islami misalnya: apabila bertemu di jalan saling mengucapkan salam dan berperilaku yang baik. System Pendidikan di SDN Pegadungan 07 Pagi Kalideres Jakarta Barat menekankan pada siswanya untuk berakhlakul karimah dan ada beberapa pembinaan akhlak dengan jalan pembiasaan pagi atau pada waktu harihari besar Islam. Selain itu apabila di lihat dari segi kualitasnya system pendidikan di SDN Pegadungan 07 Pagi menjadikan lembaga pendidikan berprestasi yang ada di kelurahan Pegadungan Kalideres Jakarta Barat, walaupun berkarakter sekolah umum tapi tetap menomor satukan pendidikan akhlak peserta didiknya.

Keunikan lokasi penelitian di SDN Pegadungan 07 Pagi Kalideres Jakarta Barat pada faktanya sekolah tersebut sebagai lembaga pendidikan yang berusaha membentuk generasi yang terbaik (handal), beriman dan bertaqwa berakhlakul karimah dan berketrampilan melalui pendidikan umum dan agama serta mayoritas peserta didiknya mendapatkan pendidikan agama dari orang tua, namun kenyataanya perilaku sehari-hari peserta didik tidak jarang melakukan tindakan diluar aturan. Sehingga peran pendidik dalam meningkatkan akhlak peserta didik sangat diperlukan untuk mengurangi tindak atau akhlak kurang baik yang dilakukan oleh peserta didik. Strategi internalisasi nilai-nilai moral keagamaan yang diterapkan dalam proses pembelajaran terdiri dari; keteladanan (modelling), analisis masalah atau kasus, penanaman nilai edukatif yang kontekstual, penguatan nilai moral yang sudah ada. Proses internalisasi di suatu lembaga tidak bisa dilakukan secara instan akan tetapi dilakukan secara terus menerus dan berkelanjutan(Munif, 2017).

\section{Hasil penelitian melalui wawancara}

Temuan atau hasil dari penelitian ini berupa hasil wawancara yang dilakukan oleh penliti kepada informan-informan yang meliputi strategi keteladanan (modeling), penanaman nilai edukatif yang kontekstual, dan penguatan nilai-nilai dalam internalisasi nilai-nilai moral di SDN Pegadungan 07 Pagi.

Hasil wawancara tentang keteladanan (modeling) dalam internalisasi nilai-niai moral, informan 1 mengemukakan:

“...strategi keteladanan internal dilakukan dengan memberikan contoh dalam proses pembelajaran ataupun program-program yang ada di sekolah. Untuk internalisasi nilai-nilai moral di lembaga ini ada yang dilaksanakan setiap hari dan ada yang dilaksanakan pada hari tertentu. Internalisasi nilai-nilai moral yang dilaksanakan setiap hari antara lain: membaca al-Qur'an tiap pagi hari, shalat dhuha yang dilaksanakan sebagian besar siswa pada saat istirahat dan Shalat Dhuhur berjama'ah yang dilaksanakan oleh para siswa dengan diimami oleh guru. Guru yang menjadi imam bukan hanya guru mata pelajaran pendidikan agama Islam saja namun guru yang merasa mampu boleh untuk menjadi imam. Untuk adzan dan iqamat dilakukan oleh siswa." (Informan 1, wawancara, pegadungan, 12/10/2020).

Hasil wawancara ini diperkuat oleh informan 2 yang mengungkapkan bahwa:

"Internalisasi nilai-nilai moral yang ada di lembaga ini adalah membiasakan anak-anak untuk mengucapkan salam ketika bertemu dengan siapapun, ramah dan memelihara senyum. Untuk mengaji pagi itu, sekarang anak-anak tanpa disuruhpun telah bergiliran dan menyadari akan tugasnya, demikian juga dalam hal berjama'ah dhuhu." (informan 2, wawancara, pegadungan, 12/10/2020). 


\section{Strategi Guru Pendidikan Agama Islam (PAI) dalam Internalisasi Nilai-Nilai Moral di Sekolah Dasar-}

Sobri

DOI: https://doi.org/10.31004/edukatif.v3i4.900

Pada hari yang lain, ketika peneliti temui lagi, beliau mengemukakan:

“... internalisasi nilai-nilai moral yang dilaksanakan setiap hari antara lain: tadarrus al-Qur'an tiap pagi hari, shalat dhuha yang dilaksanakan sebagian besar siswa pada saat istirahat dan Shalat Dhuhur berjamaah yang dilaksanakan oleh para siswa dengan diimami oleh guru. Guru yang menjadi imam bergantian antara satu dengan lainnya. Biasanya shalat dhuhur tersebut dilaksanakan pada pukul 13.00." (Informan 5, wawancara, pegadungan, 12/10/2020).

Kemudian wawancara diteruskan untuk mengetahui program mingguan yang telah diterapkan, informan 1 mengungkapkan bahwa:

"Kegiatan yang menjadi rutinan lagi yaitu ketika hari selasa diadakan kegiatan membaca asmaul husna. Di samping itu, lembaga ini juga mengadakan kegiatan Jum'at beramal, untuk melatih para siswa untuk berjiwa dermawan, membantu kepada yang membutuhkan"(Informan 1. wawancara, pegadungan, $12 / 10 / 2020)$.

Hal ini diperkuat dari penjelasan informan pendukung yang menyatakan bahwa:

"Pembiasaan baca al-Qur'an Yaasin dengan tartil dan tilawah, khususnya pada hari jumat, jam 05.3008.30 WIB. Hal tersebut dibiasakan dalam kegiatan Rohani Islam, sebagai bukti hasil pembelajaran hari jumat. Baca al-Qur'an surah Yaasin dilaksanakan setiap hari Jum'at pada jam pertama dengan dibimbing oleh guru PAI di lapangan. Kegiatan yang menjadi rutinan lagi yaitu asmaul husna, biasanya ketika hari Selasa. Di samping itu, pengembangan nilai-nilai agama di lembaga ini diterapkan agar siswa mempunyai nilai lebih dibidang keagamaan, seperti bisa baca al-Qur'an dan shalat jama'ah"(informan 5, wawancara, pegadungan, $12 / 10 / 2020)$.

“...Ada lagi istighatsah, Pak! Kegiatan tersebut diadakan saat tertentu. Sedangkan internalisasi nilainilai moral yang merupakan kegiatan ekstra kurikuler dilaksanakan secara rutin setiap Sabtu dan dijadwal dalam kurikulum serta dibina oleh masing-masing pembimbing dan dikoordinatori oleh bagian keagamaan. Internalisasi nilai-nilai moral yang sudah menjadi amalan harian di sekolah ini yaitu hafalan asmaul husna, dan ketika hari Jum'at membaca Yasin. Di samping itu, ada lagi hafalan surah-surah pendek dan itu digunakan sebagai prasyarat kenaikan kelas. Setiap tingkat harus hafal beberapa surah, namun macam-macam surahnya saya tidak hafal, nanti minta pada guru PAI saja...”(informan 6, wawancara, pegadungan, 12/10/2020).

Penguatan pendidikan nilai dalam konteks era global sangat berhubungan dalam mengatasi krisis moral (Gunawan et al., 2019). Berdasarkan hasil wawancara yang telah dipaparkan maka strategi keteladanan (modeling) dalam internalisasi nilai-nilai moral di SDN Pegadungan 07 Pagi dengan jalan: 1) keteladanan internal (internal modelling). Strategi internalisasi nilai-nilai moral di lembaga ini ada yang dilaksanakan setiap hari dan ada yang dilaksanakan pada hari tertentu. Internalisasi nilai-nilai moral yang dilaksanakan setiap hari antara lain: membaca al-Qur'an tiap pagi hari, shalat dhuha yang dilaksanakan sebagian besar siswa pada saat istirahat dan Shalat Dhuhur berjama'ah yang dilaksanakan oleh para siswa dengan diimami oleh guru. Guru yang menjadi imam bukan hanya guru mata pelajaran rumpun pendidikan agama Islam saja namun guru yang merasa mampu boleh untuk menjadi imam. Untuk adzan dan iqamat dilakukan oleh siswa. Implementasi pengembangan internalisasi nilai-nilai moral berikutnya adalah dengan dilaksanakan kegiatan mingguan yaitu Membaca Asmaul Husna, Jum'at beramal. Implementasi pengembangan internalisasi nilainilai moral berikutnya adalah dengan dilaksanakan kegiatan insidental atau temporal antaranya ada istighatsah, PHBI, kegiatan pesantren Ramadhan, halal bihalal, kegiatan Idul Adha dan sebagainya. 2) keteladanan eksternal (external modelling). Pemberian keteladanan yang dilakukan oleh pendiidk, pada hakikatnya mengacu kepada kompetensi kepribadian yang harus dimiliki oleh guru selain kompetensi sosial, pedagogik dan profesional (Karakter \& Melalui, n.d :2019). Keteladanan eksternal dilakukan dengan pemberian contoh-contoh yang baik dari para tokoh yang dapat diteladani yaitu dengan jalan pihak sekolahmenganjurkan untuk mensuri tauladani sifat-sifat Nabi Muhammad SAW yaitu shidiq, tablig, amanah dan fatonah, harus dijadikan pedoman untuk bertingkah laku dalam kehidupan sehari-hari. dan juga tokoh- 


\section{Strategi Guru Pendidikan Agama Islam (PAI) dalam Internalisasi Nilai-Nilai Moral di Sekolah Dasar- Sobri}

DOI: https://doi.org/10.31004/edukatif.v3i4.900

tokoh Islam lainnya agar senantiasa mengambil hikmah dalam setiap kisah para tokoh Islam untuk senantiasa berjuang di jalan Allah SWT.

Adapun wawancara mengenai strategi penanaman Nilai Edukatif yang kontekstual dalam internalisasi nilai-nilai moral informan 1 mengemukakan:

"Jadi menurut saya sebagai Guru PAI sesuai dengan visi sekolah, visi sekolah itukan terciptanya peserta didik yang beriman dan bertakwa kepada Tuhan Yang Maha Esa, berkarakter, cerdas dan kompetitif. Jadi antara iptek dan imtaknya harus sejalan. Terus.. Untuk mewujudkan imtaq itu ya.. karena mayoritasnya Islam ya....ya yang jelas secara intra kan ada pelajaran agama dan disamping itu ada even-even kegiatan keagamaan seperti do'a bersama, bersalaman, membaca Al Qur'an sebelum pelajaran dimulai" (informan 1, wawancara, pegadungan, 27/10/2020).

Hal ini senada dengan yang dikatakan oleh bapak Informan 5, selaku guru PAI :

"Ya... Untuk mengembangkan internalisasi nilai-nilai moral selaras dengan visi dan misi SDN Pegadungan 07 Pagi ini, di lakukan dengan cara meningkatkan ibadah mereka dengan cara membiasakan berdo'a sebelum pelajaran dimulai, membaca Al Qur'an, Saya juga sebaga Pengajar PAI" (informan 5, wawancara, pegadungan, 27/10/2020).

Tidak hanya tentang visi dan misi sekolah ada juga program ekstrakurikuler yang diadakan sekolah, hal ini diungkapakan, bahwa:

"Selama ini kami selaku pihak sekolah membuka pintu yang selebar-lebarnya untuk kegiatan-kegiatan ekstrakurikuler yang ada, selama kegiatan tersebut dapat membantu anak-anak untuk menyalurkan bakat dan minatnya, selama tidak mengganggu sekolah, kecuali pada situasi dan kondisi tertentu, seperti ada perlombaan, kan juga untuk kepentingan sekolah" (informan 1, wawancara, pegadungan, 27/10/2020).

"Ketika kegiatan keagamaan di luar jam pelajaran, beliau sangat mendukung. Keinginan beliau kalau ada kegiatan keagamaan Islam itu diikuti.. ya maksudnya agar pengalaman siswa itu bertambah. Ya tidak hanya keagamaan saja ... ya lomba atau yang berhubungan dengan kegiatan keagamaan itu ya selalu didukung dengan baik" (informan 3, wawancara, pegadungan, 27/10/2020).

Hal tersebut senada dengan yang diungkapkan oleh Informan 5, beliau mengatakan :

"Keberadaan kegiatan ekstrakurikuler ini sangat penting, karena kalau kita mau jujur dengan alokasi jam pelajaran agama Islam yang minim sekali, akan sangat sulit untuk mencapai tujuan pengajarannya. Oleh karena itu ekstrakurikuler bidang keagamaan ini cukup efektif untuk membantu tercapainya pengembangan internalisasi nilai-nilai moral di sekolah" (informan 5, wawancara, pegadungan, 27/10/2020).

Internalisasi nilai-nilai moral religius dalam proses pembelajaran adalah hal penting yang harus dikembangkan agar ilmu yang diperoleh siswa lebih bermakna (Murdiono, 2010). Berdasarkan hasil wawancara strategi penanaman Nilai Edukatif yang kontekstual dalam internalisasi nilai-nilai moral di SDN Pegadungan 07 Pagi yang sangat ditekankan: 1) para siswa dan seluruh warga sekolah untuk mengartikulasikan visi dari sekolah yaitu Terciptanya peserta didik yang beriman dan bertakwa kepada Tuhan Yang Maha Esa, berkarakter,cerdas dan kompetitif, 2) Kepala SDN Pegadungan 07 Pagi memberikan kebijakan untuk memberikan kesempatan kepada semua pembina ekstrakurikuler untuk melakukan kegiatannya selama tidak mengganggu jam belajar sekolah, 2) Menerapkan pembiasaan dalam pengembangan internalisasi nilai-nilai moral tersebut pada diri siswa. 3) Memberikan keteladanan Keteladanan di sini dimaksudkan agar seluruh warga sekolah mengikuti perbuatan dan tingkah laku yang dilakukan oleh pimpinan dan gurunya, 4) Kebersamaan dalam kegiatan membudayakan religius.

Internaslisasi adalah hal yang dijadikan sebagai penghayatan, pendalaman, penguasaan secara mendalam melalui binaan, bimbingan dan sebagainya (Munif, 2017). Strategi penguatan nilai-nilai yang ada dalam internalisasi nilai-nilai moral di SDN Pegadungan 07 Pagi dilakukan dengan memberikan motivasi. Motivasi merupakan kekuatan dalam diri seseorang baik luar maupun dalam dalam mencapai tujuan yang ditetapkan sebelumnya(Solihat \& Sundari, 2015). 1) Guru memotivasi siswa untuk Saling bekerjasama dan 


\section{Strategi Guru Pendidikan Agama Islam (PAI) dalam Internalisasi Nilai-Nilai Moral di Sekolah Dasar- Sobri}

DOI: https://doi.org/10.31004/edukatif.v3i4.900

tolong menolong ini merupakan akhlak terhadap sesama yang wajib diaplikasikan siswa, karena dengan tercipta lingkungan sekolah yang berakhlak dan tentram tanpa ada keributan yang berarti. 2) Guru memotivasi siswa untuk saling kasih mengasihi antar siswa, karena merupakan akhlak terhadap sesama yang wajib diaplikasikan siswa, jika demikian akan tercipta suasana tentram tanpa ada keributan yang berarti. 3) Guru selalu memberi motivasi pada siswa untuk berakhlak yang baik, misalnya selalu amar ma'ruf nahi mungkar terhadap sesama siswa ini lebih penting dilakukan selain kepeduliannya terhadap teman juga sebagai penanaman akhlak yang baik bagi siswa. 4) Guru memotivasi siswa untuk selalu beriman dan bertaqwa karena dengan taqwa dengan didasari iman akan mendorong untuk berakhlakul karimah sehingga akan sukses dan berhasil dalam beragama sehingga dapat menjadi makhluk yang mulia disisi Allah SWT. 5) Guru memotivasi untuk terus bersabar Allah memberikan kabar gembira dengan dipenuhi pahala yang tiada hitungannya karena banyaknya. 6) Guru memotivasi pada siswa tentang tawakal yang benar adalah menyerahkan diri kepada Allah sesudah berusaha yang berwujud jika dibacakan ayat-ayatnya akan bertambahlah keimanan mereka dan akan semakin bertawakal kepada Allah. 7) Guru memotivasi siswa bersyukur kepada Allah memberitahukan hikmah bersyukur yaitu orang akan mudah bahagia dari pada orang yang tidak bersyukur, hati tenang dan karena bisa mengontrol keinginan dan merasa puas dan rela dengan yang Allah berikan kepadanya. 8) Guru memotivasi siswa untuk berakhlak yang baik pada orang tua, pahala berbakti pada orang tua dan memberitahu dosanya jika tidak berbakti pada orang tua.

\section{KESIMPULAN}

Strategi keteladanan (modeling) dalam internalisasi nilai-nilai moral di SDN Pegadungan 07 Pagi, Internalisasi nilai-nilai moral yang dilaksanakan setiap hari antara lain: membaca al-Qur'an, shalat dhuha, dan Shalat Dhuhur berjama'ah. Adapun kegiatan mingguan yaitu : Membaca Asmaul Husna, Jum'at beramal. Kemudian kegiatan insidental atau temporal antaranya ada istighatsah, PHBI, kegiatan pesantren Ramadhan, halal bihalal, kegiatan Idul Adha dan sebagainya. Keteladanan eksternal dilakukan dengan pemberian contohcontoh yang baik dari para tokoh yang dapat diteladani seperti menganjurkan untuk mensuri tauladani sifatsifat Nabi Muhammad SAW yaitu shidiq, tablig, amanah dan fatonah.

Strategi penanaman Nilai Edukatif yang kontekstual dalam internalisasi nilai-nilai moral di SDN Pegadungan 07 Pagi yang sangat ditekankan : 1) para siswa dan seluruh warga sekolah untuk mengartikulasikan visi dan misi sekolah. 2) Memberikan kebijakan program ekstrakurikuler. 3) Menerapkan pembiasaan. 4) Memberikan keteladanan. 5) Kebersamaan dalam kegiatan membudayakan religius.

Strategi penguatan nilai-nilai yang ada dalam internalisasi nilai-nilai moral di SDN Pegadungan 07 Pagi dilakukan melalui kemampuan dan pengalaman guru dalam memberikan nasihat dan mendorong siswa untuk senantiasa bertanggung jawab dengan menanamkan untuk saling bekerjasama, tolong menolong, berakhlak yang baik, bersabar, tawakal, bersyukur dan sebagianya.

\section{DAFTAR PUSTAKA}

Akerlof. (2012). Analisis Pengaruh Pendidikan, Pelatihan, Dan Pengalaman Kerja Terhadap Produktivitas Kerja Pegawai Dinas Pertambangan Dan Energi Provinsi Papua. Journal Of Chemical Information And Modeling, 53(9), 1689-1699.

Andini, T. M. (2019). Identifikasi Kejadian Kekerasan Pada Anak Di Kota Malang. Jurnal Perempuan Dan Anak, 2(1), 13. Https://Doi.Org/10.22219/Jpa.V2i1.5636

Basrowi \& Suwandi. (2014). Dalam Penelitian Pendidikan Bahasa. 信阳师范学院, 1(1), 32. Http://EJournal.Usd.Ac.Id/Index.Php/LLT\%0Ahttp://Jurnal.Untan.Ac.Id/Index.Php/Jpdpb/Article/Viewfile/1134 5/10753\%0Ahttp://Dx.Doi.Org/10.1016/J.Sbspro.2015.04.758\%0Awww.Iosrjournals.Org 
2320 Strategi Guru Pendidikan Agama Islam (PAI) dalam Internalisasi Nilai-Nilai Moral di Sekolah DasarSobri

DOI: https://doi.org/10.31004/edukatif.v3i4.900

Firman. (2015). Analisis Data Dalam Kualitatif. Article, 4, 1-13.

Gunawan, I., Sauri, S., \& Ganeswara, G. M. (2019). Internalisasi Nilai Moral Melalui Keteladanan Guru Pada Proses Pembelajaran Di Ruang Kelas. Sosio Religi: Jurnal Kajian Pendidikan Umum, 17(1), 1-7.

Karakter, P., \& Melalui, S. (N.D.). Keteladanan Guru Di Mtsn I Langkat. 1(3), 106-125.

Kholidah, L. N. (N.D.). Pola Integrasi Nilai-Nilai Keislaman Dalam Pembelajaran Pendidikan Agama Islam Pada Lembaga Pendidikan.

Luthfiyah, F. (2015). Metode Penelitian Kualitatif (Sistematika Penelitian Kualitatif). In Bandung: Rosda Karya. Http://Www.Academia.Edu/Download/35360663/METODE_PENELITIAN_KUALITAIF.Docx

Mekarisce, A. A. (2020). Teknik Pemeriksaan Keabsahan Data Pada Penelitian Kualitatif Di Bidang Kesehatan Masyarakat. Jurnal Ilmiah Kesehatan Masyarakat, 12(33), 145-151.

Munif, M. (2017). Strategi Internalisasi Nilai-Nilai Pai Dalam Membentuk Karakter Siswa. Edureligia; Jurnal Pendidikan Agama Islam, 1(2), 1-12. Https://Doi.Org/10.33650/Edureligia.V1i2.49

Murdiono, M. (2010). Strategi Internalisasi Nilai-Nilai Moral Religius Dalam Proses Pembelajaran Di Perguruan Tinggi. Jurnal Cakrawala Pendidikan, 1(3), 99-111. Https://Doi.Org/10.21831/Cp.V1i3.239

Saleh, S. (2016). Peran Lembaga Pendidikan Dalam Membentuk Karakter Bangsa. Seminar Nasioonal Pendidikan Ilmu-Ilmu Sosial Membentuk Karakter Bangsa Dalam Rangka Daya Saing Global, 101-112.

Salmon Priaji Martana. (2006). Problematika Penerapan Metode Field Research Untuk Penelitian Arsitektur Vernakular Di Indonesia. Dimensi (Jurnal Teknik Arsitektur), 34(1), 59-66. Http://Puslit2.Petra.Ac.Id/Ejournal/Index.Php/Ars/Article/View/16458

Shidiq, U., \& Choiri, M. (2019). Metode Penelitian Kualitatif Di Bidang Pendidikan. In Journal Of Chemical Information And Modeling (Vol. 53, Issue 9). Http://Repository.Iainponorogo.Ac.Id/484/1/Metode Penelitian Kualitatif Di Bidang Pendidikan.Pdf

Solihat, E., \& Sundari, H. (2015). Learning Motivation And Vocabulary Mastery Impact On Writing English Narrative Essays. 33-40.

Tambak, S. (2016). Metode Drill Dalam Pembelajaran Pendidikan Agama Islam. Al-Hikmah: Jurnal Agama Dan Ilmu Pengetahuan, 13(2), 110-127. Https://Doi.Org/10.25299/Al-Hikmah:Jaip.2016.Vol13(2).1517

Tang, M. (2018). Pengembangan Strategi Pembelajaran Pendidikan Agama Islam (PAI) Dalam Merespon Era Digital. Fikrotuna, 7(1), 717-740. Https://Doi.Org/10.32806/Jf.V7i1.3173

Wahyudi, D., \& Alafiah, T. (2016). Studi Penerapan Strategi Pembelajaran Berbasis Multiple Intelligences Dalam Mata Pelajaran Pendidikan Agama Islam. Mudarrisa: Jurnal Kajian Pendidikan Islam, 8(2), 255. Https://Doi.Org/10.18326/Mdr.V8i2.255-282

Yusuf Sukman, J. (2017). Опыт Аудита Обеспечения Качества И Безопасности Медицинской Деятельности В Медицинской Организации По Разделу «Эпидемиологическая Безопасностьпо Title. Вестник Росздравнадзора, 4, 9-15.

https://Nasional.Kompas.Com/Read/2021/03/10/11541971/Kementerian-Pppa-Kekerasan-TerhadapPerempuan-Dan-Anak-Meningkat-Tajam-Saat. Diakses Pada Tanggal 4 Juli 2021. 